\title{
Corrigendum to "Propagation of Shock on NREL Phase VI Wind Turbine Airfoil under Compressible Flow"
}

\author{
Mohammad A. Hossain, ${ }^{1,2}$ Ziaul Huque, ${ }^{1,2}$ and Raghava R. Kommalapati ${ }^{2,3}$ \\ ${ }^{1}$ Department of Mechanical Engineering, Prairie View A\&M University, Prairie View, TX 77446, USA \\ ${ }^{2}$ Center for Energy and Environmental Sustainability, Prairie View A\&M University, Prairie View, TX 77446, USA \\ ${ }^{3}$ Department of Civil and Environmental Engineering, Prairie View A\&M University, Prairie View, TX 77446, USA \\ Correspondence should be addressed to Ziaul Huque; zihuque@pvamu.edu \\ Received 7 March 2016; Accepted 7 March 2016 \\ Copyright (C) 2016 Mohammad A. Hossain et al. This is an open access article distributed under the Creative Commons Attribution \\ License, which permits unrestricted use, distribution, and reproduction in any medium, provided the original work is properly cited.
}

In the article titled "Propagation of Shock on NREL Phase VI Wind Turbine Airfoil under Compressible Flow," [1] the name of the third author was incorrectly written as Raghava R. Kammalapati, while the correct name is Raghava R. Kommalapati. The correct author list is shown above.

\section{References}

[1] M. A. Hossain, Z. Huque, and R. R. Kammalapati, "Propagation of shock on NREL phase VI wind turbine airfoil under compressible flow," Journal of Renewable Energy, vol. 2013, Article ID 653103, 9 pages, 2013. 

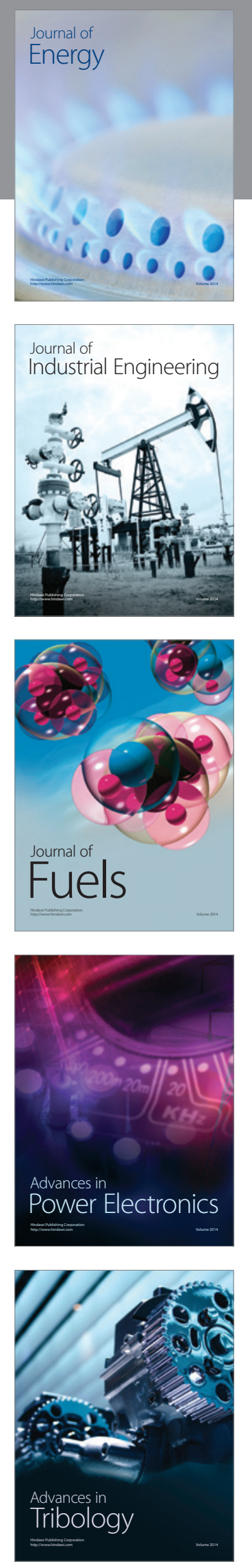
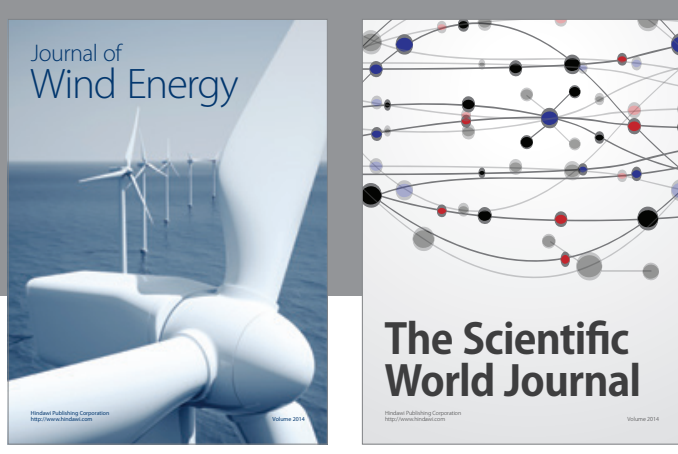

The Scientific World Journal
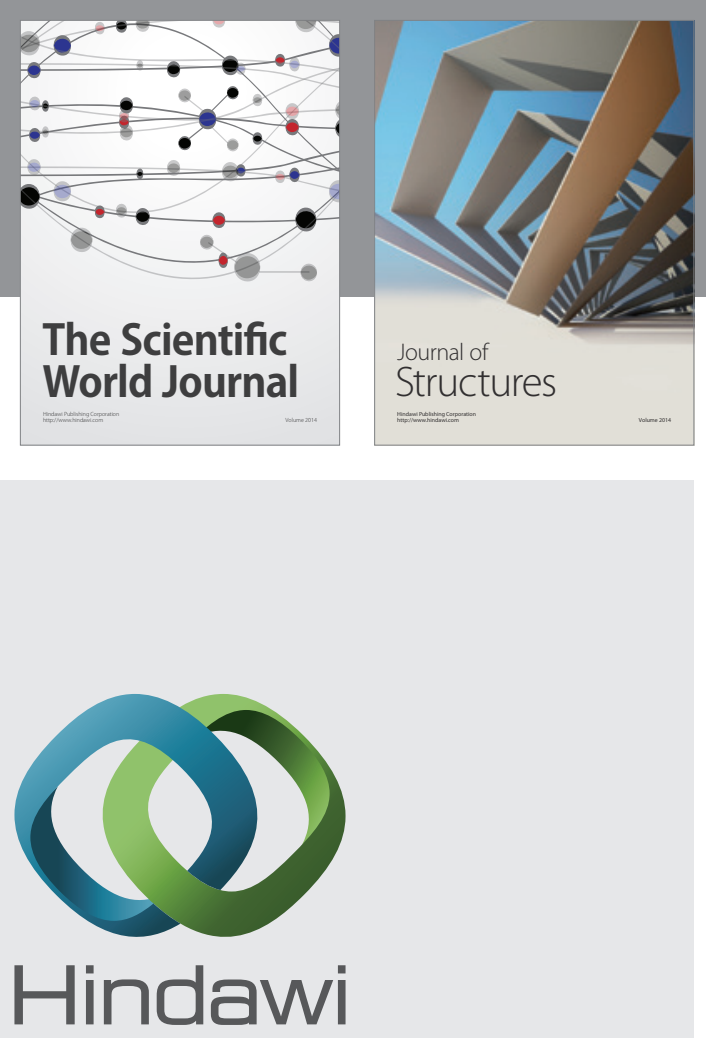

Submit your manuscripts at

http://www.hindawi.com
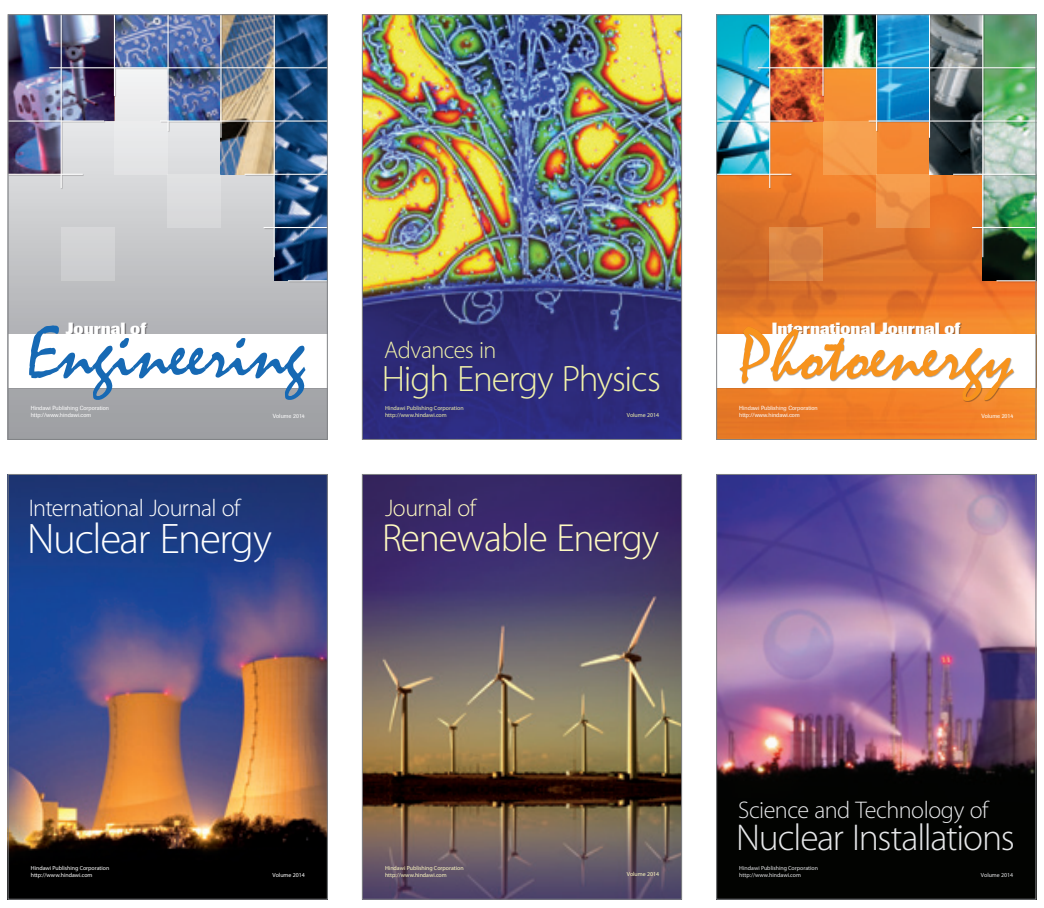
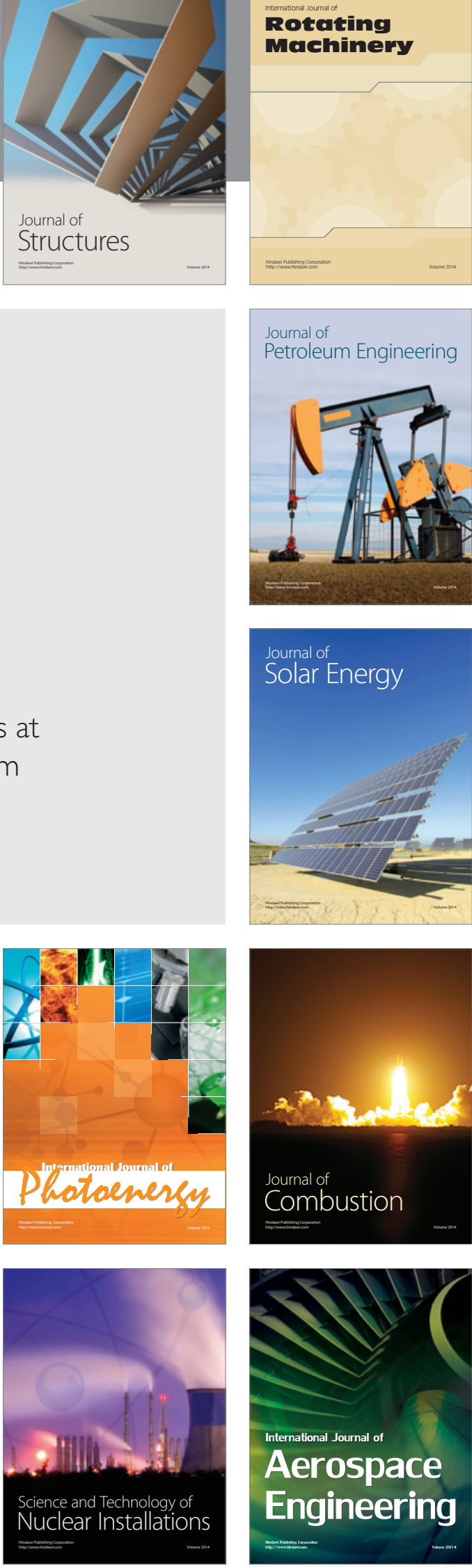